\title{
The Rural-Urban Divide in Road Safety: The Case of China
}

\author{
Becky P.Y. Loo*, W.S. Cheung and Shenjun Yao
}

Department of Geography, The University of Hong Kong, Pokfulam, Hong Kong

\begin{abstract}
Mainland China accounted for about 7\% of the global road fatalities in 2008. Road crashes happening on Chinese roads were deadly. On average, one person died in every four reported traffic crashes. Despite the scarcity of data, substantial rural-urban differences were found. In the rural areas, higher-order Highways, roads with no lighting and some heavy vehicles warrant particular attention from road safety administrations. In the 2000 s, the average number of road fatalities per 100 crashes on Expressways quadrupled. Furthermore, the rural-urban divide was not limited to inner provinces only but was found in a large part of the country. By 2008 , nearly $70 \%$ of the provincial units were having larger shares of rural population. In the long term, only a national road safety strategy will provide the necessary holistic framework for addressing the road safety problems in China systematically.
\end{abstract}

Keywords: Rural-urban divide, road safety, China, road type, road lighting, heavy vehicles, road safety strategy.

\section{INTRODUCTION}

According to the Global Status Report on Road Safety [1], there were over 1.2 million fatalities and 50 million injuries in road crashes each year in the world. In the mainland of the People's Republic of China (PRC) (that is, excluding Taiwan, Hong Kong and Macau) (hereafter mainland China), more than 250,000 road crashes causing over 70,000 deaths and 300,000 injuries were reported in 2008 [2]. Moreover, the Ministry of Public Security defines a road death as death in a road crash within 7 days after the crash [2]. This is inconsistent with the international standard of the Convention of Road Traffic in 1968, which states that "a road death is deemed to have occurred when an injured person dies within 30 days of the crash as a result of that crash" [3]. When an adjustment factor of 1.08 [4] is applied, road crashes in mainland China would account for about $7 \%$ of the total fatalities in road crashes worldwide.

The above statistics highlighted the magnitude and seriousness of road safety problems in mainland China. China is a big country of 9.6 million square kilometers. The great spatial extent suggests that its road safety problems are hardly uniform over space. In fact, the rural-urban divide in road safety has been recognized worldwide. In a road safety report on Austria, the Czech Republic, Denmark, France, Germany, Greece, Italy, the Netherlands and the United Kingdom- DUMAS, it was found that $50 \%$ to $75 \%$ of the traffic crashes causing injuries happened in urban built-up areas [5]. Nonetheless, more than $60 \%$ of the fatalities in traffic crashes happened in the rural areas. The risk of fatality in crashes was much higher on roads in rural areas than in urban areas. Furthermore, research on the driving attitude of young adults in Norway shows that there were rural-urban differences in the risk-taking driving behavior [6]. A distinctive risk-taking culture was found in the rural areas.

*Address correspondence to this author at the Department of Geography, The University of Hong Kong, Pokfulam, Hong Kong; Tel: 852-2859-7024; Fax: 852-2559-8994; E-mail: bpyloo@hku.hk
In North America, a rural-urban divide on road safety problems has also been reported. Mueller et al. [7] studied the road crash data of the United States of America (USA) from 1981 to 1983 . They found that the rate of motor vehiclepedestrian collisions was higher in urban areas but the death rate in crashes was generally higher in the rural areas. The ruralurban divide was related to vehicle speed, availability of emergency care, age and sex distribution of the population and proximity to definitive medical care. Moreover, the National Highway Traffic Safety Administration of the USA [8] showed that road fatality rates were higher in the rural than urban areas from 1997 to 2006. In 2006, 56\% of all fatal crashes in the country happened in rural areas but only $23 \%$ of the population lived there. In addition, more rural drivers were found to have been drink driving, speeding and driving unrestrained than urban drivers.

In Canada, Kmet and Macarthar [9] found that the crash fatality and hospitalization rates among children and youths in Alberta were much higher in rural than urban areas. On average, rural children and youths in Alberta were five times more likely to lose their lives and three times more likely to be hospitalized in road crashes than their urban counterparts from 1997 to 2002. The reasons were related to the greater exposure to motor vehicle travel, more risky road environment, poorer accessibility to medical care and less compliance with road safety regulations in rural areas.

Consistent with the above findings in Europe and North America, Li et al. [10] found that the percentage of prehospital deaths in traffic crashes was higher in rural than urban Taiwan. The reason was mainly attributable to unrestrained driving and the delayed emergency medical system. In mainland China, Li [11] shows that traffic crashes in mainland China mainly occurred in rural areas, on highways with higher classifications and on roads of mixed classifications. However, no in-depth study has been conducted up to date. Did a rural-urban divide in road safety also exist in mainland China? How serious was the problem? In order to allow easy international comparisons, road fatalities in mainland China have been adjusted by the factor 
of 1.08 to match the international standard of the Convention of Road Traffic throughout this paper [4].

\section{METHODOLOGY}

Disaggregate and detailed road crash data are very difficult to obtain in mainland China. To the best of the authors' knowledge, detailed nationwide crash databases by individual crash, casualty and vehicle records have never been systematically analyzed in published academic research. Nonetheless, the Ministry of Public Security does issue annual publications on road crashes in China. This paper attempts to conduct the first systematic analysis of road crashes happening in rural and urban China by making use of these publications from 2000 to 2008. Due to the nature of these data, powerful disaggregate statistical models cannot be applied. Only aggregate statistical analyses are appropriate.

Apart from the publications of the Ministry of Public Security, this study also makes use of data from two other sources. The first supplementary data source was the National Bureau of Statistics of China [12, 13] which provided demographic and socio-economic statistics of provinces, autonomous regions and municipalities in China. The second supplementary data source was China data online by All China Research Company Limited (ACMR) [14], a website authorized by the National Bureau of Statistics of China to re-disseminate non-confidential official data. This latter source provides statistical data on population and road conditions in China.
As road crashes are rare statistical events, there are random variations year by year. In scientific crash analyses, this chance element has to be taken into account. Following Mueller et al. [7], crashes are first aggregated into 3-year periods. Three three-year periods - 2000-2002, 2003-2005 and 2006-2008 - are considered in this paper. In some parts of the analysis, the discussion focuses on 2000-2002 because the crash data in the other two periods have become more limited. Moreover, the rural-urban divide is examined by the official administrative classifications. Cities and towns are considered as urban areas. Hence, urban population refers to residents of cities and towns; and rural population is defined as the population other than the urban population [12]. To identify relevant risk factors for policy intervention, two groups of variables are included in the analysis. The first group may be considered as confounding factors and they refer to factors which capture the levels of risk exposure rather than the real risk. They include variables like vehicle number, population size and length of roads. The second group may be considered as risk factors which help researchers to identify problematic areas which can be addressed by a road safety strategy [15]. These factors include road types, road lighting conditions and types of vehicles.

\section{RESULTS}

\section{General Trends}

Table 1 shows the overall trends of the growth of vehicle fleet and road crashes in China in selected years from 1970

Table 1. Summary Road Safety Records of China, 1970-2008

\begin{tabular}{|c|c|c|c|c|}
\hline 1970 & 0.4 & 55.4 & 132.0 & 83.9 \\
\hline 1980 & $\begin{array}{c}2.0 \\
(113.0 \%)\end{array}$ & $\begin{array}{c}116.7 \\
(27.4 \%)\end{array}$ & $\begin{array}{c}59.5 \\
(-40.2)\end{array}$ & $\begin{array}{c}127.1 \\
(12.5 \%)\end{array}$ \\
\hline 1985 & $\begin{array}{c}4.2 \\
(112.2 \%)\end{array}$ & $\begin{array}{c}202.4 \\
(73.4 \%)\end{array}$ & $\begin{array}{c}48.7 \\
(-18.3 \%)\end{array}$ & $\begin{array}{c}206.4 \\
(62.3 \%)\end{array}$ \\
\hline 1990 & $\begin{array}{c}9.7 \\
(133.9 \%)\end{array}$ & $\begin{array}{c}250.3 \\
(23.7 \%)\end{array}$ & $\begin{array}{c}25.7 \\
(-47.1 \%)\end{array}$ & $\begin{array}{c}222.9 \\
(8.0 \%)\end{array}$ \\
\hline 2005 & $\begin{array}{c}118.9 \\
(120.8 \%)\end{array}$ & $\begin{array}{c}450.3 \\
(-27.0 \%)\end{array}$ & $\begin{array}{c}3.8 \\
(-67.0 \%)\end{array}$ & $\begin{array}{c}206.8 \\
(-47.6 \%)\end{array}$ \\
\hline 2008 & $\begin{array}{c}154.2 \\
(29.8 \%)\end{array}$ & $\begin{array}{c}265.2 \\
(-41.1 \%)\end{array}$ & $\begin{array}{c}1.7 \\
(-54.6 \%)\end{array}$ & $\begin{array}{c}66.5 \\
(-67.9 \%)\end{array}$ \\
\hline
\end{tabular}

Notes:

1. Percentages in brackets are changes compared with previous rows.

2. "Vehicles" include automobiles and motor-cycles.

3. "Roads" include both Highways and Urban Roads. 
to 2008 (Annual changes have been analyzed but they are not presented). While the numbers of vehicles and road crashes had both increased, the number of crashes per 1,000 vehicles had been decreasing from 1970 to 2008 . During this period, the growth in vehicles in China was astonishingly high. The sharp increase in vehicle ownership was closely associated with the Open Door Policy (1979) and China's accession to the World Trade Organization (2001). Hence, the vehicle fleet has nearly tripled in eight years from 53.8 million in 2000 to 154.2 millions in 2008. From 1970 to 2008, the vehicle fleet in China has risen by more than threehundred-fold from 0.4 million to 154.2 millions.

With more vehicles on roads, traffic crashes happened more frequently as well. Table 1 shows that the trend had been rising since 1970 (55,400 crashes) until it reached its peak at around 2000 (617,000 crashes). Thereafter, the number of road crashes fell to around 265,200 crashes in 2008. Therefore, the number of crashes per 1,000 vehicles has shown a falling trend from 132.0 in 1970 to 1.7 in 2008.
Nonetheless, when the road length is also considered, the road of China had become much more dangerous throughout the 1970s, 1980s and 1990s. The number of crashes per $1,000 \mathrm{~km}$ of roads was 83.9 in 1970 . By 2000 , the figure reached an alarming rate of nearly 400 (394.9) crashes per $1,000 \mathrm{~km}$ of roads. Since 2000 , the increasing trend began to stabilize and reverse. The crash rate per $1,000 \mathrm{~km}$ of road has dropped throughout the interim years from 2000 to 2008 . The figure plunged to less than $70(66.5)$ in 2008 .

Fig. (1) shows the 5-year moving average number of crashes per 1,000 vehicles from 1972 to 2006. In general, there were some fluctuations over time but the overall trend was downward. Unfortunately, the rate of decrease has slowed down. The figure stayed at a relatively stable level throughout the 1990s. The latest five-year moving average stayed at 3.0 crashes per 1,000 vehicles in 2006. Fig. (2) further shows the 5-year moving averages of traffic injuries and deaths per 100 crashes over time. For the 5-year moving average of injuries per 100 crashes, there were greater

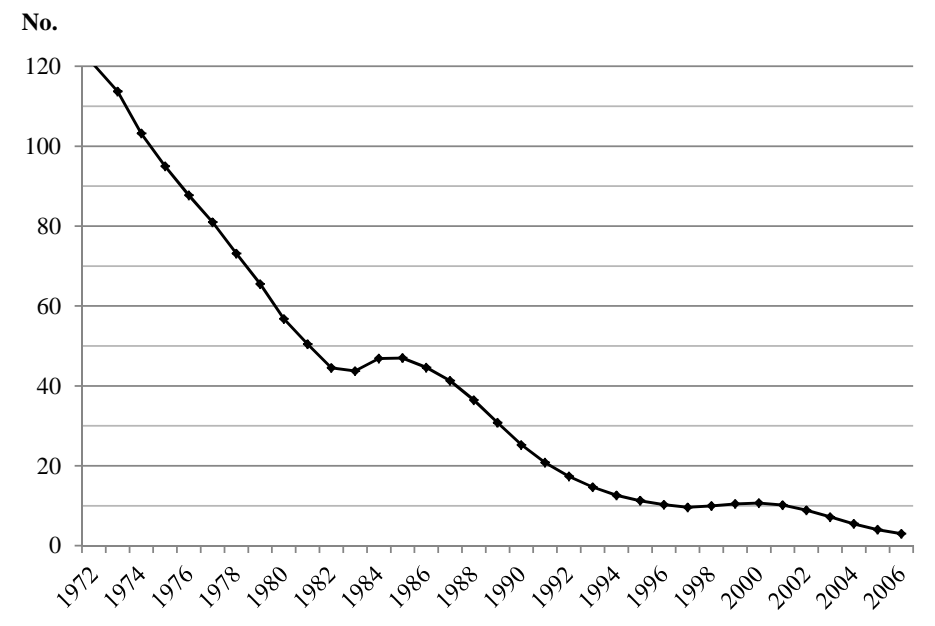

Fig. (1). 5-year averages of crashes per 1,000 vehicles in China, 1970-2008.

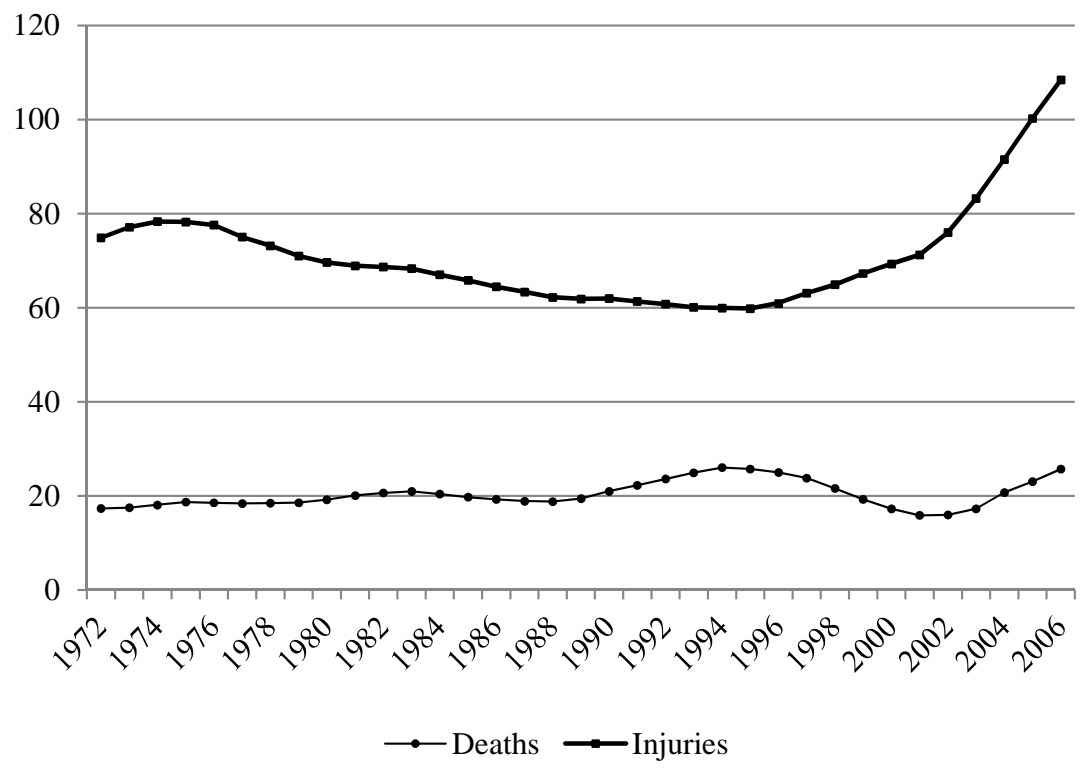

Fig. (2). 5-year averages of deaths and injuries per 100 crashes in China, 1970-2008. 
fluctuations. Overall, it rose up to the mid-1970s (78.3 injuries per 100 crashes in 1975), but then it continued to fall until it reached a steady level in the late 1980s (61.9 injuries per 100 crashes in 1989). The rate remained stable in the mid-1990s but rose rapidly again in the late 1990s to its peak of over 100 (108.5) injuries per 100 crashes in 2006. With regard to deaths per 100 crashes in China, the 5-year moving was around 20 until 1989. From 1990 onwards, there was an increase to around 25 deaths per 100 crashes (26 in 1994) in the mid-1990s but it started to fall again thereafter, reaching a low at 15.9 in 2001 . Then it gradually went up and stayed at 25.7 deaths per 100 crashes by 2006 . On average, one person died in every four traffic crashes in the PRC.

\section{The Rural-Urban Divide}

To further explore the characteristics of road crashes in China, a direct analysis of road crashes happening in the rural and urban areas of the country is conducted from 2000 to 2002. The summary is shown in Table 2. A more updated direct analysis of the 2003 to 2005 and the 2006 to 2008 periods is not possible because such data have become unavailable. Overall, the numbers of road crashes in both rural and urban China had risen. Yet, the average annual number of crashes in rural China from 2000 to 2002 (361,191 crashes) was much greater than that in urban China $(233,725$ crashes). This finding reflects that the PRC is still primarily a rural country, of which $71.8 \%$ of its land area was cultivated land, forests and grassland. Moreover, $60.9 \%$ of its population was rural in 2002 .

Also, the rural road safety problems were much more serious than that suggested by the absolute number of crashes alone. Most notably, the number of deaths in crashes in urban China decreased from 29,058 in 2000 to 26,029 in 2002 but that in rural China increased from 61,153 to 88,375 during the same period. From 2000 to 2002, the average number of deaths in road crashes in rural China $(75,986$ deaths) was nearly three times that of urban China $(26,006$ deaths). Even taking into account the greater number of crashes in rural China, the average number of deaths per 100 crashes in the rural areas (21.0) was nearly doubled that of the urban areas (11.1). In other words, a traffic casualty hurt in a rural road crash was two times more likely to die than someone hurt in an urban road crash. Like many other countries, the death rate in crashes was much higher in rural areas $[9,7,5]$.
To further examine the risk factors in rural areas, the types of roads, road lighting conditions and types of vehicles are examined from 2000 to 2008 .

\section{Types of Roads}

Fig. (3) shows the types of roads that traffic crashes happened in 2006-2008. The charts for 2000-2002 and 20032005 are not shown because they don't show much difference. Generally, about $40 \%(39.7 \%$ in $2000-2002$, $40.5 \%$ in $2003-2005$ and $41.5 \%$ in 2006-2008) of road crashes occurred on Urban Roads. In China, Highways (gonglu) which are designed to connect cities and counties generally lie in rural areas. Hence, the shares of crashes on Highways and Urban roads did suggest that traffic crashes were more likely to occur in rural China. Nonetheless, as the Highway system accounts for about $90 \%$ of the total length of the entire road network in China, we classified the Highways into six subtypes for further analysis. For crashes happening on Highways, most of them occurred on Second $(19.9 \%)$ and Third (14.4\%) Class Highways. Crashes happened least frequently on Expressways, accounted for $3.9 \%$ only in $2006-2008$.

Using the length of different types of roads as the exposure factor, the crash rates and death rates per 100 crashes happening on different types of roads are shown in Table 3. It becomes obvious that Urban Roads were much more hazardous than Highways if road length was taken into consideration. While the crash rates for different types of roads have decreased rapidly during the three periods, the crash rate on Urban Roads was over four times higher than that of Highways in the 2000-2002 and 2003-2005 periods. In 2006-2008, the crash rate on Urban Roads was over nine times higher than that of Highways. However, the situation reversed when death rates are analyzed. From 2006 to 2008, the death rate for crashes on Urban Roads (16.9) was only about half that of all crashes happening on Highways (34.5). In other words, traffic casualties on Highways are two times more likely to die than those on Urban Roads.

Among the six types of Highways, though traffic crashes happened most frequently on Second and Third Class Highways, the crash rate was found to be very much higher on First Class Highways. In 2006-2008, First Class Highways were having the highest crash rate at 495.5 crashes per $1,000 \mathrm{~km}$ of roads, and Expressways were having the second highest crash rate at 235.9 crashes per

Table 2. Number of Road Crashes and Traffic Fatalities in Rural and Urban China, 2000-2002

\begin{tabular}{|c|c|c|c|c|}
\hline & Years & No. of Road Crashes & No. of Deaths in Crashes & Deaths Per 100 Crashes \\
\hline \hline \multirow{3}{*}{ Rural China } & 2000 & 256,474 & 61,153 & 23.8 \\
\cline { 2 - 5 } & 2001 & 373,000 & 78,431 & 21.0 \\
\cline { 2 - 5 } & 2002 & 454,100 & 88,375 & 19.5 \\
\cline { 2 - 5 } & Average (2000-2002) & 361,191 & 75,986 & 21.0 \\
\hline \multirow{3}{*}{ Urban China } & 2000 & 156,386 & 29,058 & 18.6 \\
\cline { 2 - 5 } & 2001 & 243,971 & 22,931 & 9.4 \\
\cline { 2 - 5 } & 2002 & 300,819 & 26,029 & 8.7 \\
\cline { 2 - 5 } & Average (2000-2002) & 233,725 & 26,006 & 11.1 \\
\hline
\end{tabular}




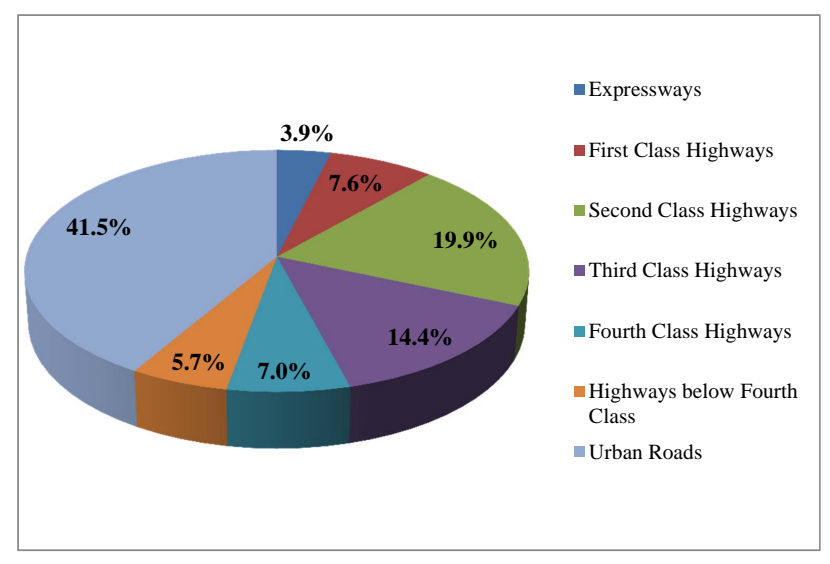

Fig. (3). Crashes in China by Road Type, 2006-2008.

Table 3. Crash and Death Rates on Different Types of Roads in China, 2000-2008

\begin{tabular}{|c|c|c|c|c|c|c|c|}
\hline & \multicolumn{6}{|c|}{ Highways } & \multirow{2}{*}{ Urban Roads } \\
\hline & Express-Ways & First Class & Second Class & Third Class & Fourth Class & Below Class IV & \\
\hline & \multicolumn{7}{|c|}{ Average Number of Crashes Per Year (in '000) } \\
\hline $2000-02$ & 18.0 & 46.0 & 134.1 & 98.2 & 35.8 & 26.8 & 236.0 \\
\hline $2003-05$ & 26.3 & 41.9 & 114.8 & 83.3 & 29.6 & 28.3 & 221.0 \\
\hline \multirow[t]{2}{*}{$2006-08$} & 12.5 & 24.7 & 64.5 & 46.6 & 22.7 & 18.3 & 134.3 \\
\hline & \multicolumn{7}{|c|}{ Average Road Length ('000 km) } \\
\hline $2000-02$ & 15.8 & 21.0 & 158.2 & 284.8 & 756.4 & 247.9 & 175.7 \\
\hline $2003-05$ & 35.0 & 33.9 & 230.0 & 334.9 & 881.5 & 354.9 & 226.0 \\
\hline \multirow[t]{2}{*}{ 2006-08 } & 53.2 & 49.9 & 274.8 & 364.3 & $1,790.1$ & $1,058.0$ & 249.1 \\
\hline & \multicolumn{7}{|c|}{ Crashes Per 1,000 km of Roads } \\
\hline $2000-02$ & $1,142.7$ & $2,187.8$ & 847.3 & 344.9 & 47.3 & 108.1 & $1,343.4$ \\
\hline $2003-05$ & 751.1 & $1,234.1$ & 498.9 & 248.7 & 33.6 & 79.8 & 978.0 \\
\hline \multirow[t]{2}{*}{$2006-08$} & 236.0 & 495.5 & 234.7 & 127.9 & 12.7 & 17.3 & 539.2 \\
\hline & \multicolumn{7}{|c|}{ Average Number of Road Deaths Per Year (in '000) } \\
\hline $2000-02$ & 2.5 & 9.2 & 30.0 & 23.1 & 8.5 & 5.7 & 23.0 \\
\hline $2003-05$ & 6.4 & 10.6 & 32.2 & 22.9 & 7.8 & 6.6 & 25.1 \\
\hline \multirow[t]{2}{*}{$2006-08$} & 6.7 & 8.3 & 23.4 & 15.6 & 6.6 & 4.7 & 22.7 \\
\hline & \multicolumn{7}{|c|}{ Deaths Per 100 Crashes } \\
\hline $2000-02$ & 14.0 & 20.0 & 22.4 & 23.5 & 23.9 & 21.2 & 9.7 \\
\hline $2003-05$ & 24.5 & 25.3 & 28.1 & 27.5 & 26.4 & 23.3 & 11.4 \\
\hline 2006-08 & 53.7 & 33.7 & 36.3 & 33.5 & 28.8 & 25.4 & 16.9 \\
\hline
\end{tabular}

$1,000 \mathrm{~km}$ of roads. In contrast, Fourth Class Highways were having a crash rate of 12.7 crashes per $1,000 \mathrm{~km}$ of roads, and Highways below Class Four were having the second lowest crash rate at 17.3 . These findings probably reflect that traffic was much heavier on the higher-order highway types. Unfortunately, detailed traffic flow data are unavailable. Although First Class Highways had the highest crash rate, the death rate in crashes on First Class Highways was not the highest. In contrast, the average deaths per 100 crashes of Expressway experienced a sharp increase from 14.0 to 53.7 during the three periods, implying that Expressways might have become a serious road safety problem causing deaths.

\section{Roads with Different Lighting Conditions}

There are some variations on the lighting conditions of roads that crashes happened. According to Table 4, a large proportion of traffic crashes in China happened in daytime $(70.2 \%$ and $59.7 \%$ in 2000-2002 and 2006-2008 respectively). For crashes happening at night, it is observed that the number of crashes and the number of deaths per 100 crashes were larger on roads without lighting than those happening on roads that lighting was available. When crashes happening at night are taken as the base, slightly above half of the crashes happened on roads without 
Table 4. Crashes in China by Road Lighting Conditions, 2000-2008

\begin{tabular}{|c|c|c|c|}
\hline & \multirow{2}{*}{ Daytime } & \multicolumn{2}{|c|}{ Night time } \\
\hline & & Lighting Available & Lighting Not Available \\
\hline & \multicolumn{3}{|c|}{ Average Number of Crashes Per Year (in '000) } \\
\hline $2000-2002$ & 417.6 & $81.6(46.0 \%)$ & $95.7(54.0 \%)$ \\
\hline $2003-2005$ & 355.6 & $91.1(48.0 \%)$ & $98.5(52.0 \%)$ \\
\hline \multirow[t]{2}{*}{$2006-2008$} & 193.4 & $65.3(49.9 \%)$ & $65.5(50.1 \%)$ \\
\hline & \multicolumn{3}{|c|}{ Average Number of Road Deaths Per Year (in '000) } \\
\hline $2000-2002$ & 62.4 & $10.0(25.4 \%)$ & $29.6(74.7 \%)$ \\
\hline $2003-2005$ & 61.3 & $14.7(29.2 \%)$ & $35.7(70.9 \%)$ \\
\hline \multirow[t]{2}{*}{ 2006-2008 } & 46.0 & $14.3(33.9 \%)$ & $27.8(66.1 \%)$ \\
\hline & \multicolumn{3}{|c|}{ Deaths Per 100 Crashes } \\
\hline $2000-2002$ & 14.9 & 12.3 & 30.9 \\
\hline $2003-2005$ & 17.2 & 16.1 & 36.2 \\
\hline $2006-2008$ & 23.8 & 21.9 & 42.5 \\
\hline
\end{tabular}

Note: Percentages in brackets are the shares calculated based on the crashes happening at night time only.

lighting. Nonetheless, about $70 \%$ of all fatalities were killed in crashes happened on roads without lighting. When compared with crashes happening at night with road lighting available (21.9 deaths per 100 crashes in 2006-2008), the death rate of crashes happening at night with no road lighting was alarmingly higher at approximately doubled the rate of crashes on roads with lighting (42.5 in 2006-2008).

Because data on the distribution of roads with different lighting conditions in China is not available, it is not possible to make a direct comparison between the road crash characteristics of rural and urban China by road lighting conditions. Nevertheless, as electricity supply and lighting facilities are more readily available in urban regions than in rural regions, it is understandable that most of the roads with lighting at night would be in urban areas while rural areas are much more likely to have no lighting facility at night.

\section{Types of Motor Vehicles}

The characteristics and common causes of road crashes and, hence, road safety measures to address them also differ by the type of motor vehicles involved. As the Ministry of Public Security used a different vehicle classification method since 2006, crashes of 2000-2002 and 2003-2005 were classified into six groups (Table 5) whereas the cases of 2006-2008 were only categorized into four types (Table 6). Despite the changes, it is still clear that the average numbers of crashes and traffic fatalities were the highest among automobiles $(211,200$ per year in 2006-2008) and motorcycles (82,700 per year in 2006-2008) throughout the study period. As automobiles and motorcycles are most common in China, it is understandable that these two types of motor vehicles were involved in crashes most frequently.

When the numbers of deaths per 100 crashes are considered, tractors, trailers and special vehicles deserve special attention from the road safety administrations. In China, special vehicles include three-wheelers, wheeled tractors and low-speed wagons [2]. In particular, tractors, trailers and special vehicles are most often found in rural China where agricultural land is concentrated. In 2003-2005, crashes involving special vehicles (32.6 deaths per 100

Table 5. Crashes in China by Types of Vehicles, 2000-2005

\begin{tabular}{|c|c|c|c|c|c|c|}
\hline & Auto-Mobiles & Motor-Cycles & Electric Vehicles & Tractors & Trailers & Special Vehicles \\
\hline & \multicolumn{6}{|c|}{ Average Number of Crashes Per Year (in '000) } \\
\hline $2000-2002$ & 431.0 & 83.1 & 281.7 & 14.3 & 4.4 & 22.3 \\
\hline \multirow[t]{2}{*}{ 2003-2005 } & 364.2 & 103.6 & 94.7 & 11.9 & 3.4 & 24.2 \\
\hline & \multicolumn{6}{|c|}{ Average Number of Road Deaths Per Year (in '000) } \\
\hline $2000-2002$ & 60.5 & 18.3 & 38.9 & 3.3 & 1.0 & 6.0 \\
\hline \multirow[t]{2}{*}{$2003-2005$} & 67.6 & 22.4 & 17.6 & 3.5 & 1.0 & 7,9 \\
\hline & \multicolumn{6}{|c|}{ Deaths Per 100 Crashes } \\
\hline $2000-2002$ & 14.0 & 22.0 & 13.8 & 23.4 & 22.7 & 26.9 \\
\hline 2003-2005 & 18.6 & 21.6 & 18.6 & 29.1 & 30.3 & 32.6 \\
\hline
\end{tabular}


Table 6. Crashes in China by Types of Vehicles, 2006-2008

\begin{tabular}{|c|c|c|c|c|}
\hline & Automobiles & Motor-Cycles & Tractors & Others \\
\hline & \multicolumn{4}{|c|}{ Average Number of Crashes Per Year (in ‘000) } \\
\hline \multirow[t]{2}{*}{$2006-2008$} & 211.2 & 82.7 & 8.8 & 3.5 \\
\hline & \multicolumn{4}{|c|}{ Average Number of Road Deaths Per Year (in '000) } \\
\hline \multirow[t]{2}{*}{$2006-2008$} & 60.5 & 18.8 & 3.0 & 1.4 \\
\hline & \multicolumn{4}{|c|}{ Deaths Per 100 Crashes } \\
\hline $2006-2008$ & 28.7 & 22.7 & 34.5 & 41.4 \\
\hline
\end{tabular}

crashes), trailers (30.3 deaths per 100 crashes) and tractors (29.1 deaths per 100 crashes) were having much higher death rates. On average, there was one traffic fatality in every three crashes involving these three types of vehicles. This figure was higher than the national average of one traffic fatality in every four crashes. In 2006-2008, "Others" which mainly include the aforementioned types of motor vehicles also had the highest death rate per 100 crashes. The death rate per 100 crashes involving "other" vehicles was staggering -- 41.4. In other words, about two persons were killed in every five traffic crashes involving these vehicles.

\section{Administrative Divisions}

Lastly, provincial data are analyzed. Fig. (4) shows the spatial distribution of road crashes per million population in the 31 provinces, autonomous regions and municipalities in China from 2006 to 2008. The spatial pattern of road crashes per million population in China in this period was quite similar to those of earlier periods. Hence, the maps of two previous periods are not shown. Generally, the rate of crashes per million population was the highest along the Eastern coast, where both the urban population and economic activities were concentrated. Shanxi in Central China and Ningxia, Chongqing as well as Xinjiang in Western China were four major exceptions.

Provincial figures can conceal substantial rural-urban differences within the province. With the availability of data on rural-urban crashes at the provincial level in 2000-2002, a more in-depth analysis by crash location is shown in Table 7.

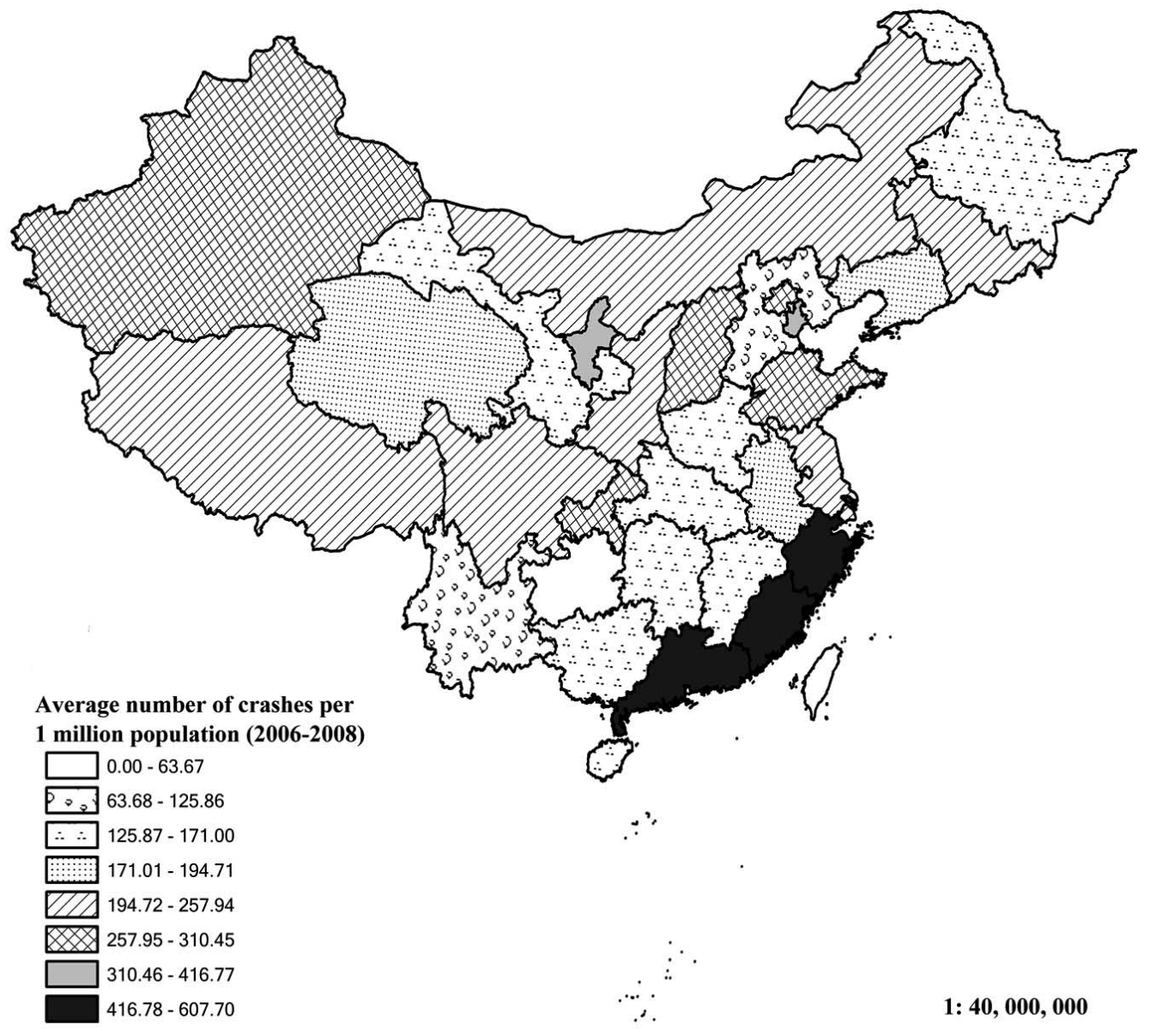

Fig. (4). Crashes per million population in China, 2006-2008. 
Table 7. Rural-Urban Road Safety Divide in China at the Provincial Level, 2000-2002

\begin{tabular}{|c|c|c|c|}
\hline & \multirow[t]{2}{*}{ Region } & \multicolumn{2}{|c|}{ Rural-Urban Ratio } \\
\hline & & Average Number of Crashes & Deaths Per 100 Crashes \\
\hline Beijing & Eastern & 0.7 & 1.1 \\
\hline Tianjin & Eastern & 8.1 & 0.8 \\
\hline Hebei & Eastern & 2.5 & 1.6 \\
\hline Shanxi & Central & 2.4 & 1.6 \\
\hline Inner Mongolia & Western & 1.1 & 1.5 \\
\hline Liaoning & Eastern & 1.2 & 1.7 \\
\hline Jilin & Central & 0.8 & 2.3 \\
\hline Heilongjiang & Central & 1.9 & 1.8 \\
\hline Shanghai & Eastern & 0.2 & 2.4 \\
\hline Jiangsu & Eastern & 1.8 & 1.9 \\
\hline Zhejiang & Eastern & 2.6 & 1.6 \\
\hline Anhui & Central & 1.6 & 2.0 \\
\hline Fujian & Eastern & 1.9 & 2.3 \\
\hline Jiangxi & Central & 3.0 & 1.4 \\
\hline Shandong & Eastern & 2.4 & 1.4 \\
\hline Henan & Central & 1.9 & 1.6 \\
\hline Hubei & Central & 1.1 & 1.8 \\
\hline Hunan & Central & 2.6 & 2.2 \\
\hline Guangdong & Eastern & 1.4 & 2.0 \\
\hline Guangxi & Western & 3.9 & 1.2 \\
\hline Hainan & Eastern & 1.0 & 2.0 \\
\hline Chongqing & Western & 1.1 & 1.8 \\
\hline Sichuan & Western & 2.0 & 1.7 \\
\hline Guizhou & Western & 1.9 & 1.7 \\
\hline Yunnan & Western & 3.0 & 2.1 \\
\hline Tibet & Western & 1.4 & 1.1 \\
\hline Shaanxi & Western & 1.6 & 1.8 \\
\hline Gansu & Western & 2.1 & 1.9 \\
\hline Qinghai & Western & 2.1 & 1.5 \\
\hline Ningxia & Western & 1.7 & 2.3 \\
\hline Xinjiang & Western & 1.6 & 1.5 \\
\hline National Average & & 2.0 & 1.7 \\
\hline
\end{tabular}

It is found that most of provincial units had higher average numbers of crashes in their rural areas. The rural-urban ratio of crashes was mostly equal to or greater than one. The only exceptions (3 out of 31) were Beijing (0.7), Jilin (0.8) and Shanghai (0.2). As a predominantly rural country, crashes happened twice (national average ratio of 2.0) as often in the rural than urban areas in China at the provincial level.

Furthermore, it is observed that all but one (Tianjin) administrative units had a higher death rate in crashes in rural areas than in urban areas. The rural-urban ratios of deaths per 100 crashes were generally above one. On average, a traffic casualty hurt in a rural road crash was about 1.7 times more likely to die than a traffic casualty hurt in an urban road crash. In seven out of the 31 provinces $(22.6 \%)$, the risk of death in rural crashes was more than doubled that of the urban crashes within the province or the municipality. They were Jilin (2.3), Shanghai (2.4), Fujian (2.3), Hunan (2.2), Hainan (2.0), Yunnan (2.1) and Ningxia (2.3). These seven provincial administrative units were areas where the rural-urban divide on the ability to survive in a traffic crash was particularly wide. Among them, Fujian, Hunan, Hainan, Yunnan and Ningxia also had more road 
crashes in the rural areas of their jurisdictions and that the death rate in rural road crashes was noticeably higher than their urban areas. The analysis highlights that the broad regional classification (Eastern, Central and Western China) can conceal substantial rural-urban divide prevailing within these administrative units.

More updated figures on crashes happening in the rural and urban areas were no longer published. Table $\mathbf{8}$ shows some more detailed information about the population and different road safety indicators in the 31 provincial administrative units in China in 2006-2008. Some noteworthy characteristics can be identified. Regarding the proportion of urban population, it can be seen that most provincial units $(67.7 \%$ or 21 out of 31$)$ were having larger shares of rural population (over 50\%). Among the exceptions, only three were having an urban population over $70 \%$. They were Beijing (84.9\%), Tianjin (77.2\%) and Shanghai $(88.6 \%)$. Seven administrative municipalities were having an urban population of over $50 \%$ but lower than $70 \%$. They were Inner Mongolia (51.7\%), Liaoning (60.1\%), Jilin (53.2\%), Heilongjiang (55.4\%), Jiangsu (54.3\%), Zhejiang $(57.6 \%)$ and Guangdong (63.4\%). The size and proportion of rural population in different provinces give us a much more realistic picture about the predominantly rural nature of the country at least up to 2008. In particular, there were still substantial rural population in Eastern China, despite the hectic economic growth and urbanization rate. The share of rural population ranged from $58.1 \%$ in Hebei to $11.4 \%$ in Shanghai along the Eastern region.

With a better understanding about the degree of urbanity in different provinces, we may take a closer look at the crash rates per $1,000 \mathrm{~km}$ of roads and deaths per 100 crashes at the provincial level. It is noteworthy that six provincial administrative units were having over 150 crashes per 1,000 $\mathrm{km}$ of roads. They were Beijing (190.5), Tianjin (255.6), Shanghai (289.2), Zhejiang (274.9), Fujian (206.5) and Guangdong (226.3). These provincial administrative units, except Fujian, were all having an urban population exceeding $50 \%$ of their total permanent population. In particular, the alarmingly high crash rate per $1,000 \mathrm{~km}$ of roads in Shanghai pointed to the dire need to step up road safety measures in this rapidly urbanizing and growing municipality. As China's process of economic growth was highly spatially concentrated, the challenges brought about by the highly concentrated economic activities (and, hence, traffic flows) need to be properly addressed. The correlation coefficient between the percentage of urban population and the crash rate per $1,000 \mathrm{~km}$ of roads is 0.8 . Overall, there was some evidence to show that the crash frequency on roads was positively associated with the urbanization rate at the provincial level.

For the death rate in road crashes at the provincial level, the correlation coefficient between the urban population proportion and death rate in road crashes was negative but slightly weaker $(-0.5)$. In other words, provinces with large rural population did seem to face a more serious road safety problem of high death rates among traffic casualties. In particular, the annual average death rate was very high (over 40 deaths per 100 crashes) in Tibet (73.7), Qinghai (66.2), Yunnan (44.3), Gansu (43.3), Guizhou (41.1), Hebei (42.7) and Guangxi (41.1), where the rural population outnumbered the urban population.

\section{CONCLUSIONS}

Road safety cannot be neglected in China. It accounted for about $7 \%$ of all road fatalities globally. The death rate in road crashes in China remained high. By 2006, the five-year moving average of deaths per 100 crashes stayed at 25.08. On average, one person died in every 4 traffic crashes. In addition, a closer examination of the available crash statistics further highlighted the existence of a significant rural-urban gap that needs to be addressed systematically. Through understanding the different characteristics of rural and urban crashes, more targeted road safety measures can be devised to alleviate the road safety problems in China in the most effective manner.

To start with, Urban Roads had alarmingly higher rates of crashes in China. They are situated in urban areas where traffic volume is high and road traffic conditions are particularly complicated. To improve road safety in urban China, emphasis should be put on urban and transport planning. Planning professionals need to assess the impact of urban development on safety problems. In addition, more frequent traffic inspection is needed. Regular speed checks, road blocks and traffic patrols should be carried out to avoid violation of traffic regulations in order to prevent the occurrence of road crashes.

Overall, the spatial distribution of road crashes also shows that the crash rate was higher in the Eastern coastal urban regions. When road length was taken as an exposure factor, Shanghai was having the highest rate of road crashes per $1,000 \mathrm{~km}$ of road among all 31 provincial units in China. Education on traffic rules and traffic rights should be promoted in to raise the awareness on road safety among road users. Furthermore, as the Eastern provinces' traffic volume is high, the comprehensive introduction of segregated lanes for motor vehicles, bicycles and pedestrians can serve the dual purpose of enhancing both efficiency and safety.

Nonetheless, rural crashes are more deadly in mainland China. In particular, the risk of fatality in crashes was notably higher on Expressways and Class One Highways connecting cities and countryside. In rural places, road safety measures should target at reducing the high death rates in road crashes. These Highways traversing the rural areas are relatively free from congestion but medical services are less accessible than in urban China. Thus, facilities such as vehicle speed monitors and speed humps or bumps should be installed to prevent speeding. Moreover, the availability of medical and emergency rescue services should be improved in rural China so as to save more lives in case of road crashes. For instance, emergency rescue teams should be set up in rural regions where crash rates are high. Special transport, such as helicopters, should be made available in remote rural areas where road transport is poorly-developed.

Furthermore, more road safety measures to improve the visibility on roads should be implemented in rural China. For crashes happening at night, about $50 \%$ of them happened on roads without lighting but roughly $70 \%$ of all deaths were killed in these crashes. Installing more street lights on roads 
Table 8. Crash and Death Rates in China by Province and by Region, 2005-2008

\begin{tabular}{|c|c|c|c|c|}
\hline & Region & $\begin{array}{l}\text { Urban Population } \\
\text { (10,000 Persons) }^{1}\end{array}$ & $\begin{array}{l}\text { Annual Average Crashes } \\
\text { Per 1,000 km of Roads }\end{array}$ & $\begin{array}{l}\text { Annual Average Deaths } \\
\text { Per } 100 \text { Crashes }\end{array}$ \\
\hline Beijing & Eastern & $1,439(84.9 \%)$ & 190.5 & 25.4 \\
\hline Tianjin & Eastern & $908(77.2 \%)$ & 255.6 & 23.7 \\
\hline Hebei & Eastern & $2,928(41.9 \%)$ & 52.8 & 42.7 \\
\hline Shanxi & Central & $1,539(45.1 \%)$ & 74.8 & 36.3 \\
\hline Inner Mongolia & Western & $1,248(51.7 \%)$ & 41.6 & 32.2 \\
\hline Liaoning & Eastern & $2,591(60.1 \%)$ & 72.0 & 33.6 \\
\hline Jilin & Central & $1,455(53.2 \%)$ & 73.2 & 30.4 \\
\hline Heilongjiang & Central & $2,119(55.4 \%)$ & 39.1 & 34.7 \\
\hline Shanghai & Eastern & $1,673(88.6 \%)$ & 289.2 & 28.5 \\
\hline Jiangsu & Eastern & $4,169(54.3 \%)$ & 118.2 & 33.9 \\
\hline Zhejiang & Eastern & $2,949(57.6 \%)$ & 274.9 & 21.9 \\
\hline Anhui & Central & $2,485(40.5 \%)$ & 76.1 & 32.0 \\
\hline Fujian & Eastern & $1,798(49.9 \%)$ & 206.5 & 19.7 \\
\hline Jiangxi & Central & $1,820(41.4 \%)$ & 55.0 & 28.6 \\
\hline Shandong & Eastern & $4,483(47.6 \%)$ & 105.0 & 24.5 \\
\hline Henan & Central & $3,397(36.0 \%)$ & 62.4 & 24.1 \\
\hline Hubei & Central & $2,581(45.2 \%)$ & 44.3 & 26.6 \\
\hline Hunan & Central & $2,689(42.2 \%)$ & 53.8 & 33.2 \\
\hline Guangdong & Eastern & $6,048(63.4 \%)$ & 226.3 & 18.2 \\
\hline Guangxi & Western & $1,838(38.2 \%)$ & 75.6 & 41.1 \\
\hline Hainan & Eastern & $410(48.0 \%)$ & 75.8 & 35. \\
\hline Chongqing & Western & $1,419(50.0 \%)$ & 75.0 & 15.7 \\
\hline Sichuan & Western & $3,044(37.4 \%)$ & 104.4 & 19.3 \\
\hline Guizhou & Western & $1,104(29.1 \%)$ & 19.7 & 61.5 \\
\hline Yunnan & Western & $1,499(33.0 \%)$ & 28.0 & 44.3 \\
\hline Tibet & Western & $65(22.7 \%)$ & 13.7 & 73.7 \\
\hline Shaanxi & Western & $1,584(42.1 \%)$ & 71.0 & 28.8 \\
\hline Gansu & Western & $845(32.2 \%)$ & 38.6 & 43.3 \\
\hline Qinghai & Western & $227(41.0 \%)$ & 19.512 & 66.2 \\
\hline Ningxia & Western & $278(45.0 \%)$ & 117.1 & 24.7 \\
\hline Xinjiang & Western & $845(39.7 \%)$ & 44.2 & 39.9 \\
\hline
\end{tabular}

Key:

* Numbers in brackets are shares of urban population in total population.

Note:

1. Population figures were of 2008

2. Provinces with urban population over $50 \%$ of its population are shaded in light grey.

should be a direct method. Nevertheless, funding and resources in rural China may be inadequate; and some of the roads in rural China are located in remote areas with no electricity. To lessen the road safety problem with limited resources, segments of roads where road crashes happened most frequently could be identified as hazardous road locations. In a high-density urban context, dangerous road locations are likely to exhibit characteristics of hot spots, which are spatially concentrated at highly specific locations like intersections [16]. However, dangerous road locations in rural areas are more likely to present themselves as hot zones, which cover longer sections of roads with multiple risk factors like long slopes [16]. A systematic program to identify dangerous road locations should take these spatial characteristics into consideration [16]. In the rural context, lighting facilities should be installed with high priority at hazardous hot zones. Also, warning signs should be placed at these locations in order to alert drivers. Furthermore, drivers 
should be educated to develop the habits of keeping their headlights on all the time at night and sound their sirens to alert others when they make a turn on roads without lighting at night. All in all, more measures to improve the visibility and safety should be launched on rural roads without lighting facilities.

Besides, road safety measures in rural areas should target at promoting the safe use of tractors, trailers and special vehicles. One should bear in mind that crashes involving tractors, trailers and special vehicles had exceptionally high death rates. These three types of vehicles are most often found in rural China as they are always used by farmers on agricultural land. More directions and training on using these vehicles should be given. Talks and other publicity campaigns should be carried out to raise farmers' awareness on road safety. In the longer term, a licensing system could be introduced to the drivers of tractors, trailers and special vehicles. Subsidies could also be given to farmers to maintain their tractors, trailers and special vehicles and/or to replace old ones with safer ones.

Moreover, these rural road safety improvement measures should not be restricted to inner provincial units only. Beyond the broad regional classifications, there was a negative relationship between the proportion of urban population and the death rate per 100 crashes at the provincial level. In other words, the rural road safety problems are prevalent in a large part of China. Such challenges should best be taken up by the central government with a national road safety strategy. Currently, a road safety strategy is still lacking in China [11]. In the future, a national road safety strategy can be developed based on the nine road safety strategy components of (1) vision; (2) objectives; (3) targets; (4) action plan; (5) evaluation and monitoring; (6) research and development; (7) quantitative modelling; (8) institution framework; and (9) funding [17]. Such a road safety strategy not only shows the determination of the central government in addressing the road safety problems in China but also lays out a clear division of labour among governments in formulating and implementing specific road safety plans. More standardization in various aspects of the road safety strategy is required. In particular, the "Law of the People's Republic of China on Road Traffic Safety", which came into effect in May, 2004 [18] was a step in this direction to facilitate more comparable crash statistics to be collected in different parts of mainland China.

Setting up quantified road safety targets with different levels to take into account different characteristics of crashes happening in rural and urban areas can be an effective means. The setting of realistic, yet challenging, quantified road safety targets in a large country like China is not easy. However, recent research has shown that there are substantial benefits of setting quantitative targets in improving road safety [19-21]. Moreover, once these road safety targets are set, careful monitoring is crucial in sustaining its effectiveness for the overall strategy [22, 23]. Looking into the future, a national road safety strategy will provide the necessary holistic national framework for addressing the road safety problems in China by taking into account the different characteristics of crashes in the rural and urban areas effectively.

\section{ACKNOWLEDGEMENTS}

This research is funded by the Research Grant Council General Research Fund (HKU 7472/07H).

\section{REFERENCES}

[1] World Health Organization. "Global Status Report on Road Safety”. Switzerland: World Health Organization 2009.

[2] Ministry of Public Security of the People's Republic of China, Quan guo dao lu jiao tong shi gu tong ji zi liao hui bian (China's road crashes statistical book). Beijing: Qun Zhong Chu Ban She.

[3] United Nations Economic Commission for Europe, Convention of Road Traffic in 1968. Available at: http://www.unece.org/trans/ conventn/crt1968e.pdf, 1993.

[4] G. Jacobs, A. Aeron-Thomas and A. Astrop, Estimating Global Road Fatalities. Crowthorne: Transport Research Laboratory 2000.

[5] Organisation for Economic Co-operation and Development (OECD), Safety on Roads: What's the Vision? OECD Publishing 2002.

[6] Eiksund S, "A geographical perspective on driving attitudes and behaviour among young adults in urban and rural Norway," Safety Science, vol. 47, pp. 529-536, 2009.

[7] B.A. Mueller, F.P. Rivara and A.B. Bergman, "Urban-rural location and the risk of dying in a pedestrian-vehicle collision," The Journal of Trauma, vol. 28, no. 1, pp. 91-94, 1988.

[8] National Highway Traffic Administration Traffic Safety Facts 2006: Rural/Urban Comparison. Washington, DC: National Center for Statistics and Analysis, US Department of Transportation, 2008.

[9] L. Kmet and C. Macarthur "Urban-rural differences in motor vehicle crash fatality and hospitalization rates among children and youth," Accident Analysis and Prevention, vol. 38, pp. 122-127, 2006.

[10] M.D. Li, J.L. Doong, K.K. Chang, T.H. Lu and M.C. Jeng, "Difference in urban and rural accident characteristics and medical service utilization for traffic fatalities in less-motorized societies", Journal of Safety Research, vol. 39, pp. 623-630, 2008.

[11] L.R. Duan, "Road Safety in China: Problems and Strategies," in Road Safety-Strategy and Implementation, S.C Wong, W.T. Hung and H.K. Lo, Eds. Shenzhen: China Public Security Publisher, pp. 51-71, 2002.

[12] National Bureau of Statistics of China, China City Statistical Yearbook. Beijing: China Statistics Press, various years.

[13] National Bureau of Statistics of China, China Statistical Yearbook. Beijing: China Statistics Press, various years.

[14] All China Research Co. Ltd. (ACMR), China data online. Available at: http://chinadataonline.org/, 2008.

[15] B.P.Y. Loo, S.C. Wong, W.T. Hung and H.K. Lo, "A review of the road safety strategy in Hong Kong," Journal of Advanced Transportation, vol. 41, pp. 3-37, 2007.

[16] B.P.Y. Loo, "The identification of hazardous road locations: a comparison of the blacksite and hot zone methodologies in Hong Kong," International Journal of Sustainable Transportation, vol. 3, no. 3, pp. 187-202, 2009.

[17] B.P.Y. Loo, W.T. Hung, H.K. Lo and S.C. Wong, "Road safety strategies: a comparative framework and case studies," Transport Reviews, vol. 25, pp. 613-639, 2005.

[18] National People's Congress of the PRC, Legislative Affairs Commission of the Standing Committee, Law of the People's Republic of China on Road Traffic Safety available at http://www. gov.cn/english/laws/2005-09/07/content_29966.htm, 2003 (last accessed on 21st July, 2009).

[19] A. Tolon-Becerra, X. Lastra-Bravo and F. Bienvenido-Barcena, "Proposal for territorial distribution of the 2010 EU road safety target," Accident Analysis and Prevention, vol. 41, no. 5, pp. 10081015, 2009.

[20] S.C. Wong and N.N. Sze, "Is the Effect of Quantified Road Safety Targets Sustainable?" Safety Science, vol. 48, no. 9, pp. 1182-1188, 2010 . 
[21] R.E. Allsop, N.N. Sze, S.C. Wong. "An update on the association between setting quantified road safety targets and road fatality reduction," Accident Analysis and Prevention, vol. 43, pp. 12791283,2011

[22] R.E. Allsop, "Road Safety Work: Implementation and Monitoring Now and Pragmatism about the Longer Term," in Road Safety-
Strategy and Implementation, S.C. Wong, W.T. Hung and H.K. Lo, Eds. Shenzhen: China Public Security Publisher, pp. 19-31, 2002.

[23] R.E. Allsop, "Britian's 11-year road safety strategy beyond midterm and in a european context," International Journal of Sustainable Transportation, vol. 3, no. 3, pp. 141-159, 2009.

(C) Loo et al.; Licensee Bentham Open.

This is an open access article licensed under the terms of the Creative Commons Attribution Non-Commercial License (http://creativecommons.org/licenses/by-nc/ 3.0/) which permits unrestricted, non-commercial use, distribution and reproduction in any medium, provided the work is properly cited. 